\title{
DRIVERS AND OUTCOMES OF CORPORATE IDENTITY MANAGEMENT
}

\author{
Cláudia Simões, Open University Business School, United Kingdom
}

\begin{abstract}
In order to compete in a changing and dynamic environment many companies, develop competitive strategies grounded at the corporate level. The management of the perceptions of a corporation is emerging as a key management tool as organizations last longer than products. Corporate identity is one possible route for establishing a corporate image among audiences. Corporate identity portrays a notion of identity transposed to organizations. Such concept conveys an abstract idea suggesting that every organization has its own personality, singularity and individuality (Bernstein, 1984) - that is, its own character. Corporate identity can be a key tool for transmitting consistent images to internal and external stakeholders and has implications into business differentiation, survival and profitability (Simões et al. 2005). Corporate identity management (CIM) coveys the idea that there are dimensions of corporate identity that are possible to control and manage and that companies differ in the extent to which they manage their corporate identities. This study explores the relationship between CIM and other managerial variables. The paper attempts to theoretically ground drivers and outcomes of CIM. It proposes that CIM is the articulation of the business unit differentiation strategy and that it is a tool used by companies concerned with stakeholders (e.g., customers and employees) management. Additionally, there are business outcomes of CIM: stakeholder commitment and business performance.
\end{abstract}

Dimensions of CIM. Simões et al. (2005) specified the following dimensions of corporate identity that ought to be managed internally at the business unit level: "(1) the endorsement of consistent behavior through the diffusion of a company's mission, values, and goals; (2) the expression and pursuit of brand and image consistency in the organization's symbols and forms of communication; and (3) the implementation, support, and maintenance of visual systems." (p. 153). The authors reached a three-dimensional scale that measures levels of internal corporate identity management: i) mission and values dissemination; ii) consistent image implementation; and, iii) visual identity implementation.

Drivers of CIM. Business strategy. Strategy involves an organization in developing an inimitable and beneficial position by relating several activities. Corporate and brand identity are considered in the literature as a source of differentiation and competitive advantage. Corporate identity is concerned with how the company comprehends itself, its behaviors and how it wants to be perceived. As such, it can be used to differentiate an organization implying a strategic link between a differentiation strategy and corporate identity. The strategy followed is, therefore, an antecedent for the level of engagement in CIM, with companies that emphasize a generic differentiation strategy tending to highlight their CIM. Stakeholder orientation. Stakeholder theory maintains that companies have responsibilities towards a variety of audiences such as stockholders, customers and employees. Stakeholder orientation can be seen as the degree to which companies take account of or try to respond to different stakeholders' expectations. The effective management of corporate identity leads to a favorable image among an organization's stakeholders. Consumers become more willing to buy a company's products and employees are more predisposed to work for it. It is, therefore, proposed that companies with a higher level of stakeholder orientation tend to present higher level of CIM.

Outcomes of CIM. Stakeholder commitment. Stakeholder management and CIM aim to develop positive feelings and behavior among the organization's audiences towards the corporation. They encourage stakeholder commitment. Stakeholder commitment reflects the way in which stakeholders are continuously inclined to respond favorably towards the company. It is anticipated that companies with higher profiles and a stronger identity, image and reputation will have more committed and loyal stakeholders. CIM aims to influence stakeholders, encouraging positive behavior towards the company. Stakeholder commitment is, therefore, a potentially important outcome of a more pro-active CIM (e.g., Simões and Mason 2012). Business performance. General and specific performance outcomes have been attributed to corporate identity and/or to specific aspects of its management. For example, it has been suggested that the corporate image and/or identity affect organizational performance; has a positive effect on sales and profitability levels; and, assists business growth. Since there are controllable aspects of CI that can be managed internally, it seems reasonable to propose that companies which are more pro-active in their internal (or external) CIM will present higher levels of business performance.

The over-arching effect that CI may have in companies' existence and motion opens a wide range of research avenues. CI's amplitude and complexity compel investigation to draw on specific perspectives and parts of its management.

References available upon request 